Article

\title{
Based on entrepreneurial culture to discuss the correlation between sustainable innovation capability and patent
}

\author{
Aimin Qi \\ Guangxi Development Research Institute of Intellectual Property ，School of Law , GuangXi \\ University for Nationalities, Nanning, China. \\ Email: 1309978103@qq.com
}

\begin{abstract}
Currently the rapid growth of global economy has the competition among high-tech industries develop from regional to global, and the competition becomes fierce. In face of such fierce competition in global high-tech industry, it is realized that tangible assets could no longer be the differentiation basis, but intangible assets are regarded as the differentiation capital. An enterprise with sustainable innovation would dominate the world market and enhance the international competitiveness of domestic economy. When internal entrepreneurial culture is prevalent, an enterprise would naturally promote the innovation capability. Such a point of view also explains more popular of the innovative products or services of some enterprises than those with larger scales.

Aiming at employees in high-tech industry in Guanxi Province, total 500 copies of questionnaire are randomly distributed, and 337 valid copies are retrieved, with the retrieval rate $67 \%$. The research results reveal significantly positive correlations between 1.entrepreneurial culture and sustainable innovation capability, 2.sustainable innovation capability and patent, and 3.entrepreneurial culture and patent. According to the results, suggestions are proposed, expecting to explain how a high-tech business outperforms in the changeable digital era and acquires the sustainable innovation capability and patent to grasp the opportunity.

Key words: entrepreneurial culture, persistence, innovation capability, patent, high-tech industry
\end{abstract}

\section{Introduction}

In face of the environment with economic globalization and rapid knowledge development in the $21^{\text {st }}$ century, the delivery of information is accelerated due to network technology, and the acquisition of message becomes easier. The past obstacles caused by space and geography have been eliminated. The competition among high-tech industries develops from regional to global, and the competition becomes fiercer. Especially, when information could be rapidly acquired, the technology and knowledge possessed by a high-tech business would no longer be the exclusive advantage. Under currently rapid growth of global economy, high-tech businesses in science and technology parks are increasing the demands for information electronics because of PC, mobile phones, digital cameras, and digital TV. Nonetheless, in face of the globally fierce competition in high-tech industry, the past differentiation bases of quality, cost, economic planning, customer services, and mass advertising, under the spread of best practice, are gradually imitated by other competitors. It is realized that tangible assets are no longer the differentiation basis, while intangible assets are considered as the differentiation capital for high-tech businesses.

Sustainable innovation is a critical key in the increasing profits of an enterprise. It might integrate some old markets to create new opportunities, destroy existing markets, assist enterprises in acquiring the leading status in the market, and overthrow the original market 
leaders. An enterprise with sustainable innovation could dominate the world market and enhance the international competitiveness of domestic economy. For this reason, sustainable innovation could enhance markets, the success of an enterprise, and the economic growth of a nation. Accordingly, business managers and governments in the world are aware of the importance of sustainable innovation. When internal entrepreneurial culture is prevalent in an enterprise, the innovation capability would be naturally enhanced. Such a point of view also explains why some enterprises are more popular with the innovative products or services than others with larger scales. Based on the viewpoint of entrepreneurial culture, the correlation between sustainable innovation capability and patent is studied, expecting to explain how a high-tech business outperforms in the changeable digital era and grasps opportunities by the acquisition of sustainable innovation capability and patent.

\section{Literature review}

\subsection{Entrepreneurial culture}

Qiu \& Wan (2015) pointed out culture as the common recognition and common core attitudes and measures of members in a nation or an enterprise. Most researchers considered that culture was reflected on common cognition and standard operation programs. Foss \& Saebi (2017) stated that culture was the unique product of human beings, was developed slowly and implicitly, and was not easily defined and transmitted to another nation or enterprise. Maisonobe et al. (2016) pointed out various dimensions of culture, some of which could enhance or inhibit the innovation capability of an enterprise. Culture which encouraged continuous innovation could assist an enterprise in maintaining the leading advantage in innovation. Kim \& Park (2017) contained three attitudes and three measures in corporate culture and sustainable innovation. Schumpeter (2017) mentioned that benefits generated from existing products or services were the key factors in the sustainable innovation of an enterprise. The willingness of resource allocation referred to the consideration of sacrificing the assets which could currently generate profits, including current revenues and successfully innovated products, so that the enterprise could acquire the opportunities in the next-generation innovation to further acquire large success. Bonakdar et al. (2017) indicated that future market orientation allowed an enterprise comprehending the limit and restriction of current technologies and considered that the new-generation technology could be the mainstream in the future market. Current profits could guarantee the future development, while future profits presented uncertain risks, which could not be predicted and managed. It was extremely important for an enterprise cultivating and promoting the employees with risk tolerance attitudes and capabilities.

Referring to Zhang \& Tang (2017), entrepreneurial culture is divided into three dimensions in this study.

(1) Resource allocation: In consideration of sacrificing assets which could currently generate profits, including current revenues and successfully innovated products, so that the enterprise could acquire the opportunity in the next-generation innovation.

(2) Market orientation: Comprehending the limit and restriction of current technologies and considering that the new-generation technology could be the mainstream in the future market.

(3) Risk tolerance: An enterprise cultivating and promoting the employees with risk tolerance attitudes and capabilities.

\subsection{Sustainable innovation capability}

Kim \& Lee (2015) pointed out the source of innovation from the development and extension of existing knowledge and proposed several definitions that it could promote and improve existing products and services for either new products or services. Innovation 
therefore could appear on products, programs, or organizational activities. Dimitratos et al. (2016) indicated that employees were the source of an enterprise's innovation capability, which was transferrable knowledge to generate new knowledge and further develop new products and services or improve existing products and services (Piening et al., 2016). Klamer (2016) proposed that sustainable innovation capability was a primary key allowing an enterprise or a nation possessing high competitiveness internationally. Any enterprises would encounter important strategy selection that the improvement or reinforcement of existing capabilities could acquire short-term success, while the investment in sustainable innovation capability could benefit the long-term development of an enterprise (Gloet \& Samson, 2016).

Referring to Lee \& Lee (2017), sustainable innovation capability contains two dimensions in this study.

(1) Technological innovation: The improvement of existing products, services, and programs, which could result in better performance than past production and service processes, or promote brand-new products and services to satisfy customer needs.

(2) Product innovation: An enterprise reinforcing the research \& development and design abilities, promoting the product quality, developing new products or services conforming to the market demand, and evaluating the goal achievement of the sales amount and customer satisfaction of new products or services.

\subsection{Patent}

Sheng \& Chien (2015) explained that, in order to protect the deserved rights of an invention or a creation, it was applied for patent in local intellectual property protection agencies. After being examined the conformity to the patent act, it would be approved the patent and the owner was authorized the right to exclude others manufacturing, selling, offering for sales, using, or importing the article without the agreement. McCahery et al. (2016) described utility patent as the owner had the exclusive right to exclude others applying the utility, selling, offering for sales, or importing the utility without the agreement. Duane \& Fisher (2016) explained patent as the government sector authorized the inventor exclusive rights for producing, selling, or using the invention in certain periods. Patent contained invention, utility model, and appearance design. Kocak et al. (2017) indicated that a patent owner enjoyed the exclusive rights for producing, using, selling, and importing the invention and creation. He \& Wintoki (2016) also mentioned that any units or individuals could not produce, manufacture for business, use, sell, and import patent products without the agreement of the patent owner; it would infringe the patent to use the patent of utility or produce, manufacture for business, use, sell, and import products directly acquired with the utility without the permission of the patent owner.

Referring to Li et al. (2017), patent covers three invention, utility, and design in this study.

(1) Invention patent: referring to an invention regulated in the patent act must present the technology and at least satisfy the utilization of natural rules and techniques to perform on the object or usage.

(2) Utility patent: It could define that utility is the technical ideas generated with natural rules to perform on the shape, structure, or device of objects for innovation, and to generate certain new function or enhance effectiveness.

(3) Design patent: It could define design as to promote the quality, friendliness, and high value with the shape, pattern, color, or the combines of objects to enhance the product competitiveness and the visual comfort on the use.

2.4 Research hypothesis

Wani \& Ali (2015) regarded corporate knowledge existing in human capitals and 
defined it as individual knowledge, skills, and experiences of employees; business managers displayed the value in the enterprise by setting objectives to form the corporate culture and the strategic direction to influence employees' application of the human capital. Höflinger et al. (2018) pointed out the success factors in entrepreneurial culture as exploring new knowledge and applying existing knowledge. A manager being willing to undertake the risk of using existing products and technologies for developing new markets or customers might generate limited new knowledge, but could deepen employees' existing knowledge and skills and have the employees understand the gap of existing knowledge and skills to pursue new knowledge and skills. McKelvey \& Ljungberg (2017) indicated that, when an enterprise turned to new and different technologies, businesses, and products/services and the manager were willing to allocate resources to establish a lab or a research team and encourage the engagement of employees, the employees would acquire new knowledge and enhance opportunities to identify the abilities and apply the knowledge and skills to the enterprise to further enhance the human capital of the enterprise. For this reason, the following hypothesis is proposed in this study.

H1: Entrepreneurial culture presents significantly positive correlations with sustainable innovation capability.

Zhao et al. (2015) proved that sustainable innovation capability would result in patent for a company, and patent would bring in excess market remuneration. Jeong et al. (2016) considered that sustainable innovation capability, in which many enterprises invested, could enhance the number of patents as the representative of the technological power of a company. The empirical results showed the remarkably positive correlations between sustainable innovation capability and number of patents. Paruchuri \& Awate (2017) indicated that some companies invested large amount of money in sustainable innovation activities, i.e. high sustainable innovation capability, to have the companies acquire profitable new products or patents. In this case, sustainable innovation capability increased with the number of patents. The following hypothesis is therefore proposed in this study.

H2: Sustainable innovation capability shows remarkably positive correlations with patent.

Sumo et al. (2016) mentioned that, in the environment with entrepreneurial culture, the willingness of resource allocation allowed a company easily being a project organization, without the structure being easily rigid, and easily enhancing the internal competition and encouragement. New knowledge acquired through exploration, such as contact with heterogeneous markets/customers or technologies, could improve or reset the experience accumulated and opportunity identified in the routine knowledge to promote the patent of the enterprise. Kim (2016) considered that entrepreneurial culture with higher risk tolerance could better learn from mistakes in the exploration of new knowledge and structure experiences in databases, manuals, or processes to revise existing structured knowledge; besides, it was regarded as the accumulation of patents and the symbol of advance. Pauli (2016) indicated that entrepreneurial culture preferred resource allocation to have the organization present flexibility and cross-department integration ability to rapidly respond to external environmental changes for integrating or eliminating existing knowledge in the organization, creating new knowledge conforming to contemporary environment, and effectively enhancing the patent. Consequently, the following hypothesis is proposed in this study.

H3: Entrepreneurial culture reveals notably positive correlations with patent. 


\section{Research method}

\subsection{Method and model}

The goodness-of-fit test in LISREL model is generally measured from overall model fit (i.e. external quality of model) and internal quality of model. In regard to overall model fit test, the common goodness-of-fit evaluation indices contain (1) " $\chi 2$ ratio" (Chi-Square ratio), standing for the difference between actual theoretical model and expected value, which is better below 3, (2) goodness of fit index (GFI) and adjusted goodness of fit index (AGFI), which show better goodness-of-fit when close to 1, (3) root mean square residual (RMR), reflecting the square root of "fit residual variance/covariance mean", which is better below 0.05 , and (4) incremental fit index (IFI), revealing excellent goodness-of-fit of the model when above 0.9 .

The evaluation indicators for the internal quality of model in LISREL include (1) SMC (square multiple correlation) of individual manifest variables, i.e. R2 of manifest variables and latent variables, which should be above 0.5 , (2) component reliability (@) of latent variable, as the Cronbach's $\alpha$ of the observation indicator of the latent variable, which should be above 0.6 , and (3) average variance extracted of latent variable, which is calculated by dividing the $\mathrm{R} 2$ sum of manifest variables in a latent variable with the number of manifest variables to reveal the percentage of the latent variable being measured with the manifest variables; the value is better above 0.5 .

\subsection{Research sample and subject}

Employees in high-tech industry in Guanxi Province are randomly distributed 500 copies of questionnaire in this study. Total 337 valid copies are retrieved, with the retrieval rate $67 \%$. The retrieved questionnaire data are analyzed with the statistics software.

\subsection{Reliability and validity test}

Validity refers to a measurement scale being able to actually measure what a researcher intends to measure. The common validity contains "content validity", tending to qualitative test, "criterion validity", using known external criteria and the correlation coefficient of the test for the evaluation, and "construct validity" used for evaluating the theoretical consistency of the measurement to other observable variables. The questionnaire content in this study is based on past theories and referred to the actual conditions of the research objects to design the measuring tool, which could truly express the essence of the affair and the complete representativeness, to ensure the content validity of the questionnaire. The final commonality estimate of factor analysis is applied to test the construct validity of the measurement items, and the validity appears in $0.8 \sim 0.9$, showing good validity test result of the questionnaire.

\section{Result and Discussion}

4.1 Model goodness-of-fit test

"Maximum likelihood method" is applied in this study for the estimation. The analysis results achieve the convergence. Overall speaking, the overall model fit indices in this study pass the test, Table 1, fully reflecting favorable external quality of the model.

Table 1 Model analysis result

\begin{tabular}{|c|c|c|c|}
\hline \multirow{4}{*}{$\begin{array}{c}\text { Overall } \\
\text { goodness-of-fit }\end{array}$} & Evaluation indicator & Judgment standard & Result \\
\cline { 2 - 4 } & $p$-value & $p$-value above 0.05 & 0.000 \\
\cline { 2 - 4 } & $\chi 2 /$ d.f. & $<3$ & 1.833 \\
\cline { 2 - 4 } & GFI & $>0.9$ & 0.991 \\
\cline { 2 - 4 } & AGFI & $>0.9$ & 0.912 \\
\cline { 2 - 4 } & CFI & $>0.9$ & 0.975 \\
\hline
\end{tabular}




\begin{tabular}{|c|c|c|c|}
\hline \multirow{2}{*}{ RMR } & $\begin{array}{c}\text { below 0.05, } \\
\text { below 0.025 excellent }\end{array}$ & 0.016 \\
\cline { 2 - 4 } & RMSEA & $\begin{array}{c}0.05 \sim 0.08 \text { good } \\
\text { below } 0.05 \text { excellent }\end{array}$ & 0.027 \\
\cline { 2 - 4 } & NFI & $>0.9$ & 0.946 \\
\cline { 2 - 4 } & IFI & $>0.9$ & 0.938 \\
\hline
\end{tabular}

\subsection{Path relationship test}

In terms of the test of internal quality of model, the square multiple correlation (SMC) of manifest variables is above 0.5 (Table 2 \& Table 3), revealing good indices of the latent variables. Furthermore, latent variables of entrepreneurial culture, sustainable innovation capability, and patent show the component reliability above 0.6 , and the average variance extracted of the dimensions is also above 0.5 (Table 4), apparently conforming to the requirements for internal quality of model.

Table 2 SMC of variable to dimension

\begin{tabular}{|c|c|c|}
\hline \multicolumn{3}{|c|}{ entrepreneurial culture } \\
\hline resource allocation & market orientation & risk tolerance \\
\hline 0.73 & 0.78 & 0.82 \\
\hline
\end{tabular}

Table 3 SMC of variable to dimension

\begin{tabular}{|c|c|c|c|c|}
\hline \multicolumn{2}{|c|}{ sustainable innovation capability } & \multicolumn{3}{|c|}{ patent } \\
\hline $\begin{array}{c}\text { technological } \\
\text { innovation }\end{array}$ & $\begin{array}{c}\text { product } \\
\text { innovation }\end{array}$ & invention patent & $\begin{array}{c}\text { utility } \\
\text { patent }\end{array}$ & design patent \\
\hline 0.75 & 0.77 & 0.74 & 0.81 & 0.85 \\
\hline
\end{tabular}

Table 4 Component reliability 與 average variance extracted of variable

\begin{tabular}{|l|l|l|l|}
\hline item & $\begin{array}{l}\text { entrepreneurial } \\
\text { culture }\end{array}$ & $\begin{array}{l}\text { sustainable } \\
\text { innovation } \\
\text { capability }\end{array}$ & patent \\
\hline $\begin{array}{l}\text { component } \\
\text { reliability }\end{array}$ & 0.833 & 0.851 & 0.876 \\
\hline $\begin{array}{l}\text { average variance } \\
\text { extracted }\end{array}$ & 0.82 & 0.84 & 0.88 \\
\hline
\end{tabular}

From the model analysis result in Table 5, entrepreneurial culture and sustainable innovation capability (0.852) present positive and significant correlations, sustainable innovation capability and patent $(0.883)$ show positive and remarkable correlations, and entrepreneurial culture and patent (0.845) appear positive and notable correlations that H1, $\mathrm{H} 2$, and $\mathrm{H} 3$ are supported. The research hypothesis test results of this study are shown in Table 6.

Table 5 Linear structural model analysis result

\begin{tabular}{|c|c|c|c|}
\hline evaluation item & parameter/evaluation standards & result & $\mathrm{t}$ \\
\hline \multirow{3}{*}{$\begin{array}{c}\text { internal } \\
\text { goodness-of-fit }\end{array}$} & $\begin{array}{c}\text { entrepreneurial culture } \rightarrow \text { sustainable } \\
\text { innovation capability }\end{array}$ & 0.852 & $29.37^{* *}$ \\
\cline { 2 - 4 } & $\begin{array}{c}\text { sustainable innovation capability } \rightarrow \\
\text { patent }\end{array}$ & 0.883 & $35.49^{* *}$ \\
\cline { 2 - 4 } & entrepreneurial culture $\rightarrow$ patent & 0.845 & $26.15^{* *}$ \\
\hline
\end{tabular}


Table 6 Hypothesis test

\begin{tabular}{|l|c|c|c|c|}
\hline $\begin{array}{l}\text { research } \\
\text { hypothesis }\end{array}$ & correlation & empirical result & $\mathrm{P}$ & result \\
\hline H1 & + & 0.852 & 0.00 & supported \\
\hline H2 & + & 0.883 & 0.00 & supported \\
\hline H3 & + & 0.845 & 0.00 & supported \\
\hline
\end{tabular}

\section{Conclusion}

The research results show that a high-tech business with entrepreneurial culture is willing to allocate resources, orient on future market, presents attitudes and measures with risk tolerance to affect the employees' value and consensus. Culture is the exclusive product of human beings and is slowly and implicitly developed, which is not easily defined and transmitted to another nation or enterprise. A high-tech business is mainly composed of and led by people; the construction of intelligent capital is the same. Corporate culture is implicit in all employees so that they are affected by specific value and consensus, when accumulating and applying knowledge. The acquisition of new knowledge would be distinct to create the sustainable innovation capability of the high-tech business. Apparently, the attitudes and measures covered in entrepreneurial culture would largely affect the organizational capital of a high-tech business to change the knowledge accumulation and application methods and processes, create the sustainable innovation capability, and further influence the patent.

\section{Suggestion}

By summarizing the research results and findings, the following practical suggestions are proposed in this study.

1. A high-tech business should consider the real meanings behind sustainable innovation and precede strategic regulation. The future sustainable innovation could aim at multinational technology licensing and the establishment of technology transaction platforms. Besides, the cooperation with the governmental policies could activate the research and development outcomes and intelligent properties. The sustainable innovation and patent could be developed with network organization.

2. A high-tech business should reinforce the absorption ability of external knowledge and technology as well as cultivate the ability to identify and utilize external knowledge valuable for the organization, e.g. enhancing employees' abilities through internal education and training, selecting professional talents with rich experiences, knowledge, and techniques when recruiting new members, and enhancing investment in research and development to enhance the effective acquisition of knowledge.

3. A high-tech business should develop the internal knowledge integration ability. Knowledge is power, particularly in the knowledge-based economic era. It relies on the establishment and promotion of entrepreneurial culture to enhance the knowledge saving and reinforce the competitive advantage of a high-tech business.

Conflicts of Interest: The authors declare no conflict of interest

\section{Reference}

Bonakdar, A.; Frankenberger, K.; Bader, M. A.; Gassmann, O. Capturing value from business models: the role of formal and informal protection strategies. International Journal of Technology Management, 2017, 73(4), 151-175. 
Dimitratos, P.; Buck, T.; Fletcher, m.; Li, N., The motivation of international entrepreneurship: The case of Chinese transnational entrepreneurs. International Business Review, 2016, 25(5), 1103-1113.

Duane, J. N.; Fisher, S., The startup equation: A visual guidebook to building, launching and scaling your startup. Asia: McGraw-Hill Education. 2016

Foss, N.; Saebi, T., Fifteen years of research on business model innovation: How far have we come, and where should we go? Journal of Management, 2017, 43(1), 200-227.

Gloet, M.; Samson, D., Knowledge Management and Systematic Innovation Capability, International Journal of Knowledge Management, 2016, 12, 54-72.

He, Z.; Wintoki, M. B., The cost of innovation: R\&D and high cash holdings in U.S. firms. Journal of Corporate Finance, 2016, 41, 280-303.

Höflinger, P. J.; Nagel, C.; Sandner, P., Reputation for technological innovation: Does it actually cohere with innovative activity? Journal of Innovation \& Knowledge, 2018, 3(1), 26-39.

Jeong, E.; Yun, J. J.; Won, D.; Park, K.; Yang, J.; Park, J., The relationship between technology, business model, and market in autonomous car and intelligent robot industries, Technological Forecasting and Social Change, 2016,103, 142-155.

Kim, J.; Lee, S., Patent databases for innovation studies: A comparative analysis of USPTO, EPO, JPO and KIPO. Technological Forecasting and Social Change, 2015, 92, 332-345.

Kim, M., Geographic scope, isolating mechanisms, and value appropriation, Strategic Management Journal, 2016, 37(4), 695-713.

Kim, W.; Park, J., Examining Structural Relationships between Work Engagement, Organizational Procedural Justice, Knowledge Sharing, and Innovative Work Behavior for Sustainable Organizations, Sustainability, 2017, 9(205), doi:10.3390/su9020205

Klamer, A., The value-based approach to cultural economics? Journal of Cultural Economics, 2016, 40(4), 365-373.

Kocak, A.; A. Carsrud; S. Oflazoglu., Market, entrepreneurial, and technology orientations: impact on innovation and firm performance, Management Decision, 2017, 55(2), 248-270.

Lee, M.; Lee, S., Identifying new business opportunities from competitor intelligence: An integrated use of patent and trademark databases. Technological Forecasting $\mathcal{E}$ Social Change, 2017 119, 170-183.

Li, X.; Qiao, H.; Wang, S., Exploring evolution and emerging trends in business model study: a co-citation analysis, Scientometrics, 2017,111(2), 869-887.

Maisonobe, M; Eckert, D.; Grossetti, M.; Jégou, L.; Milard, B., The world network of scientific collaborations between cities: domestic or international dynamics? Journal of Informatics, 2016 10(4), 1025-1036.

McCahery, J. A.; Z. Sautner; L. T. Starks., Behind the scenes: The corporate governance preferences of institutional investors., The Journal of Finance ,2016,71 (6):2905-2932.

McKelvey, M., \& Ljungberg, D., How public policy can stimulate the capabilities of firms to innovate in a traditional industry through academic engagement: the case of the Swedish food industry. RED Management, 2017, 47(4), 534-544.

Paruchuri, S.; Awate, S., Organizational knowledge networks and local search: The role of intra-organizational inventor networks. Strategic Management Journal, 2017, 38(3), 657675.

Pauli, U. (2016). Enhancing SMEs" Growth by Investing in Organizational Capital. Entrepreneurial Business and Economics Review 4(3): 103.

Piening, E. P., Salge, T. O., \& Schäfer, S. (2016). Innovating across boundaries: A portfolio perspective on innovation partnerships of multinational corporations. Journal of World Business, 51(3), 474-485.

Qiu, J., and Wan, C. (2015). Technology spillovers and corporate cash holdings. Journal of Financial Economics, 115(3), 558-573. 
Schumpeter, J. A., Corporate short-termism is a frustratingly slippery idea, The economist, 2017, February 18, 50

Sheng, M. L.; I. Chien., Rethinking organizational learning orientation on radical and incremental innovation in high-tech firms, Journal of Business Research, 2015,69, 2302-2308.

Sumo, R.; W. van der Valk; A. van Weele ; C. Bode., Fostering incremental and radical innovation through performance-based contracting in buyer-supplier relationships, International Journal of Operations \& Production Management 2016, 36(11), 1482-1503.

Wani, T. A.; Ali, S. W., Innovation diffusion theory review \& scope in the study of adoption of smartphones in India, Journal of General Management Research, 2015, 3(2), 101-118.

Zhang, G.; Tang, C., How could firm's internal R\&D collaboration bring more innovation? Technological Forecasting and Social Change, 2017,125, 299-308.

Zhao, J.; Xi, X.; Yi, S., Resource allocation under a strategic alliance: How a cooperative network with knowledge flow spurs co-evolution. Knowledge-Based Systems, 2015, 89, 497-508. 